\title{
DYNAMIC PRICING SCHEME FOR THE JAVA-BALI SYSTEM RESIDENTIAL LOAD
}

\author{
Eko Adhi Setiawan ${ }^{1,2}$, Andy Prakoso ${ }^{1,2}$,Vhania Maulia $^{1 *}$ \\ ${ }^{1}$ Department of Electrical Engineering, Faculty of Engineering, Universitas Indonesia, Kampus UI \\ Depok, Depok 16424, Indonesia \\ ${ }^{2}$ Tropical Renewable Energy Center TREC, Faculty of Engineering, Universitas Indonesia, Kampus \\ UI Depok, Depok 16424, Indonesia
}

(Received: August 2019 / Revised: October 2019 / Accepted: November 2019)

\begin{abstract}
The monopoly electricity market in Indonesia uses flat tariffs but is being encouraged to change to dynamic pricing. Dynamic pricing scenarios have been implemented in many Western countries with various types of schemes. This paper discusses dynamic pricing scenarios based on residential load and generation in the Java-Bali system. The tariff scheme is a combination of critical peak pricing (CPP) and time-of-use (TOU). The CPP runs for only a few hours each year depending on the gas power plant operation. TOU will be used with peak and off-peak schedules as determined based on residential load characteristics. The gas power plant is a reference in designing the CPP rates because it is used to meet peak loads if other plants are unable to meet requirements and its cost of generating electricity is high compared to other power plants. The dynamic pricing scheme is simulated for a residential load. Then, the load reduction during peak times and the impact of reducing electricity consumption in the Java-Bali system is analyzed.
\end{abstract}

Keywords: $\quad$ Basic cost of supply; Critical peak; Dynamic pricing; Electricity tariff; Time of use

\section{INTRODUCTION}

Dynamic pricing is a program launched by electric utilities to study a various rate structures to lower peak demand for electricity (Ton et al., 2013). Taylor et al. (1975), Braithwait (2000), King and Chatterjee (2003), EPRI (2008) and Faruqui et al. (2010) present the application of dynamic pricing. Dynamic electricity prices are a demand side management technique that can reduce peak loads by providing different prices at different times according to demand. A peak in the load profile is the result of unregulated requests when additional capacity is needed. This peak load capacity remains inactive during the off-peak period, which results in the loss of opportunity costs and system inefficiency. Dynamic pricing can shift demand from peak to off-peak and help avoid large capital investments.

The retail electricity market generally offers flat rate or dynamic price. Prices remain unchanged regardless of demand in the first case, while when prices are dynamic the price per unit of electricity increases or decreases as electricity consumption changes. However, generation costs to meet peak demand are compared to off-peak demand because most peak time generating units have higher operating costs compared to basic load units. Although fixed rates allow customers' electricity bills to be free of uncertainty, this can lead to high capacity additions. While reducing

\footnotetext{
${ }^{*}$ Corresponding author's email: vhaniam@gmail.com, Tel. +62-21-7270078, Fax. +62-21-7270077 Permalink/DOI: https://dx.doi.org/10.14716/ijtech.v10i6.3698
} 
peak demand, dynamic prices can also provide every consumer the opportunity to reduce their bill and maintain a constant level by changing consumption patterns and therefore shifting loads.

\section{METHODOLOGY}

\subsection{Load Profile}

The literature review for dynamic pricing was carried out using references from countries including the United States, the United Kingdom and certain Asian countries that have implemented dynamic pricing. This literature was studied to develop scenarios. The method uses secondary data from the utility grid company, which is processed and analyzed to form dynamic electricity prices.

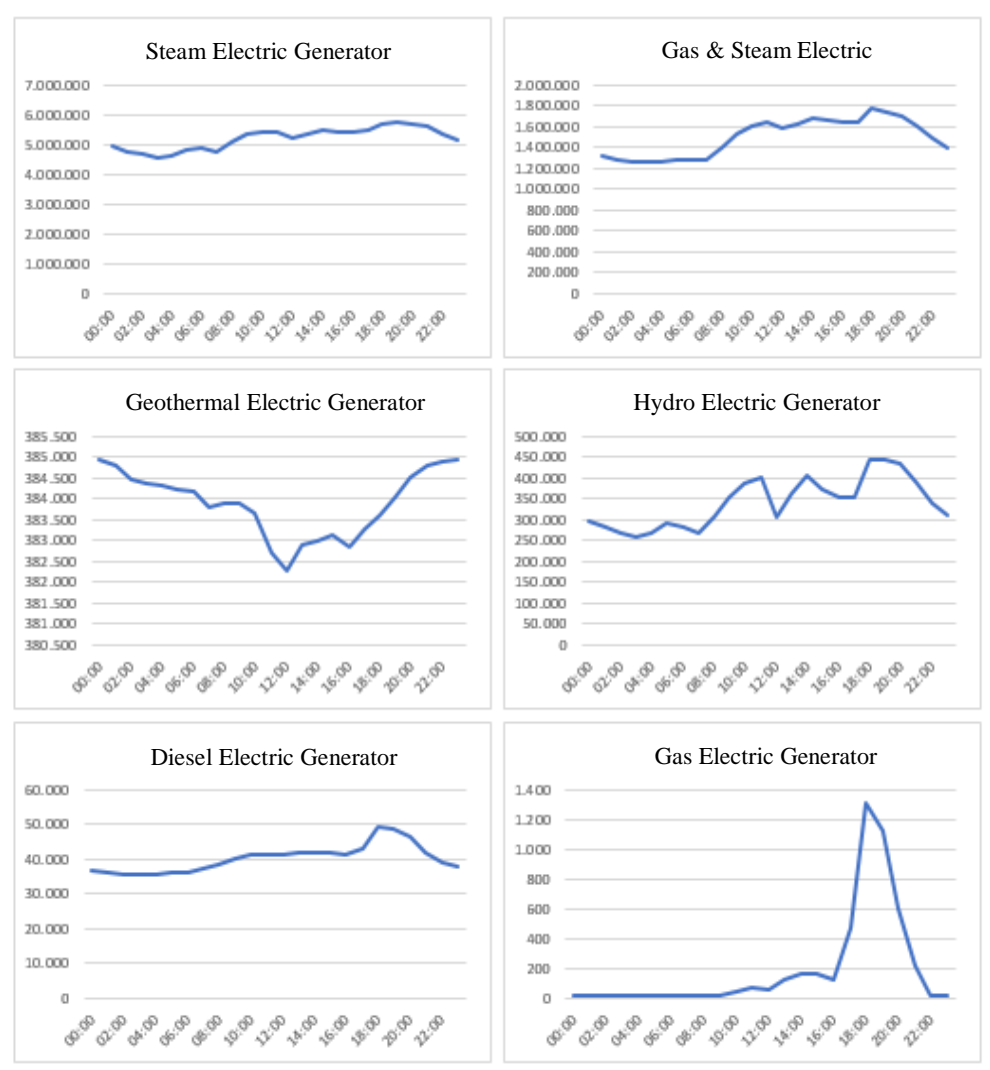

Figure 1 Load profile of every generator

The data on electricity generation cost (biaya pokok penyediaan, BPP) from each utility grid power generator and independent power producer (IPP) have been provided.

Table 1 Electricity generation cost/BPP

\begin{tabular}{|c|c|c|}
\hline No & $\begin{array}{l}\text { Power Plant - Electric } \\
\text { Generator List }\end{array}$ & $\begin{array}{c}\text { Production Base } \\
\text { Cost }(\mathrm{Rp} / \mathrm{kWh})\end{array}$ \\
\hline 1. & $\begin{array}{l}\text { Gas Powered Electric } \\
\text { Generator }\end{array}$ & Rp 10,090.35 \\
\hline 2. & $\begin{array}{l}\text { Diesel Powered Electric } \\
\text { Generator }\end{array}$ & Rp 1,879.85 \\
\hline 3. & $\begin{array}{l}\text { Hydroelectric Power } \\
\text { Plant }\end{array}$ & $\operatorname{Rp} 897.5$ \\
\hline 4. & $\begin{array}{l}\text { Hydroelectric Power } \\
\text { Plant - IPP }\end{array}$ & $\operatorname{Rp} 882.5$ \\
\hline 5. & $\begin{array}{l}\text { Gas and Steam Powered } \\
\text { Electric Generator }\end{array}$ & $R p 1,094.81$ \\
\hline
\end{tabular}

\begin{tabular}{|c|c|c|}
\hline No & $\begin{array}{l}\text { Power Plant - Electric } \\
\text { Generator List }\end{array}$ & $\begin{array}{l}\text { Production Base } \\
\text { Cost }(\mathrm{Rp} / \mathrm{kWh})\end{array}$ \\
\hline 6. & $\begin{array}{l}\text { Gas and Steam Powered } \\
\text { Electric Generator - IPP }\end{array}$ & Rp 1,143.35 \\
\hline 7. & Geothermal Power Plant & $\operatorname{Rp} 1,980.14$ \\
\hline 8. & $\begin{array}{l}\text { Geothermal Power Plant } \\
\text { - IPP }\end{array}$ & Rp 1,070.13 \\
\hline 9 . & $\begin{array}{l}\text { Steam Powered Electric } \\
\text { Generator }\end{array}$ & Rp 806.71 \\
\hline 10. & $\begin{array}{l}\text { Steam Powered Electric } \\
\text { Generator - IPP }\end{array}$ & Rp 1,014.84 \\
\hline
\end{tabular}




\subsection{Gas Power Plant}

A gas power plant does not operate throughout the year but only on certain days when it is necessary to fulfil peak loads. Based on the data, in one year the gas power plant only operated for 41 days at different operating times. However, the plants will operate based on economic considerations. The most inexpensive operating costs will be the first operated, then proceeds to the more expensive plants (Faruqui et al., 2011).

Which generator is the least expensive can be determined by the variable component. One variable component that significantly influences operating costs is the primary fuel source, which can be used as a basic reference in determining where the lowest cost generator will be prioritized compared to more expensive ones until the electricity load is fulfilled.

\subsection{Residential Design}

After collecting information on the electricity generation cost and the actual electricity tariff per hour, the data on residential load is gathered from the feeders from October-November 2018. Table 2 presents the residential load during holiday, weekday, weekend and all day.

Table 2 Residential load data

\begin{tabular}{|c|c|c|c|c|}
\hline Time & Holiday & Weekday & Weekend & All Day \\
\hline 00.00 & 0.19 & 0.19 & 0.16 & 0.18 \\
\hline 01.00 & 0.18 & 0.18 & 0.15 & 0.17 \\
\hline 02.00 & 0.18 & 0.18 & 0.15 & 0.16 \\
\hline 03.00 & 0.17 & 0.17 & 0.14 & 0.16 \\
\hline 04.00 & 0.17 & 0.17 & 0.14 & 0.16 \\
\hline 05.00 & 0.17 & 0.18 & 0.15 & 0.16 \\
\hline 06.00 & 0.16 & 0.17 & 0.14 & 0.15 \\
\hline 07.00 & 0.16 & 0.16 & 0.13 & 0.14 \\
\hline 08.00 & 0.16 & 0.15 & 0.13 & 0.14 \\
\hline 09.00 & 0.17 & 0.15 & 0.14 & 0.14 \\
\hline 10.00 & 0.17 & 0.15 & 0.14 & 0.15 \\
\hline 11.00 & 0.17 & 0.16 & 0.14 & 0.15 \\
\hline 12.00 & 0.18 & 0.16 & 0.14 & 0.15 \\
\hline 13.00 & 0.18 & 0.16 & 0.14 & 0.15 \\
\hline 14.00 & 0.17 & 0.16 & 0.14 & 0.15 \\
\hline 15.00 & 0.17 & 0.17 & 0.14 & 0.16 \\
\hline 16.00 & 0.18 & 0.17 & 0.14 & 0.15 \\
\hline 17.00 & 0.18 & 0.17 & 0.15 & 0.16 \\
\hline 18.00 & 0.21 & 0.21 & 0.17 & 0.19 \\
\hline 19.00 & 0.22 & 0.21 & 0.17 & 0.19 \\
\hline 20.00 & 0.22 & 0.22 & 0.17 & 0.20 \\
\hline 21.00 & 0.23 & 0.22 & 0.18 & 0.20 \\
\hline 22.00 & 0.23 & 0.22 & 0.17 & 0.20 \\
\hline 23.00 & 0.21 & 0.20 & 0.17 & 0.18 \\
\hline Average & 0.18 & 0.18 & 0.15 & 0.16 \\
\hline Max & 0.23 & 0.22 & 0.18 & 0.20 \\
\hline Hour & 21.00 & $20.00-23.00$ & 21.00 & $20.00-22.00$ \\
\hline Min & 0.16 & 0.15 & 0.13 & 0.14 \\
\hline Hour & $06.00-08.00$ & $08.00-10.00$ & $07.00-08.00$ & $07.00-08.00$ \\
\hline
\end{tabular}

During the period October to November 2018 there is a national holiday, in addition to the weekdays and weekends. The load characteristics and patterns are clearly shown in Figure 2 . The average combined load is used as a reference because when compared to the workday and weekend load curves, it is more or less the same as peak and off-peak times, although even though the peak on weekends is relatively lower than the workdays. On this curve the peak time for the residential load occurs between 20.00 and 22.00, which is different from the national peak load at 18.00. Determination of peak and off-peak time for this residential load is calculated by comparing the average load for one day by $\mathrm{kWh}$ consumed per hour. If the $\mathrm{kWh}$ at that time is greater than the average $\mathrm{kWh}$, it is determined as peak time. Conversely, if the $\mathrm{kWh}$ at that time is lower than the average $\mathrm{kWh}$ then it is determined as off-peak time. 


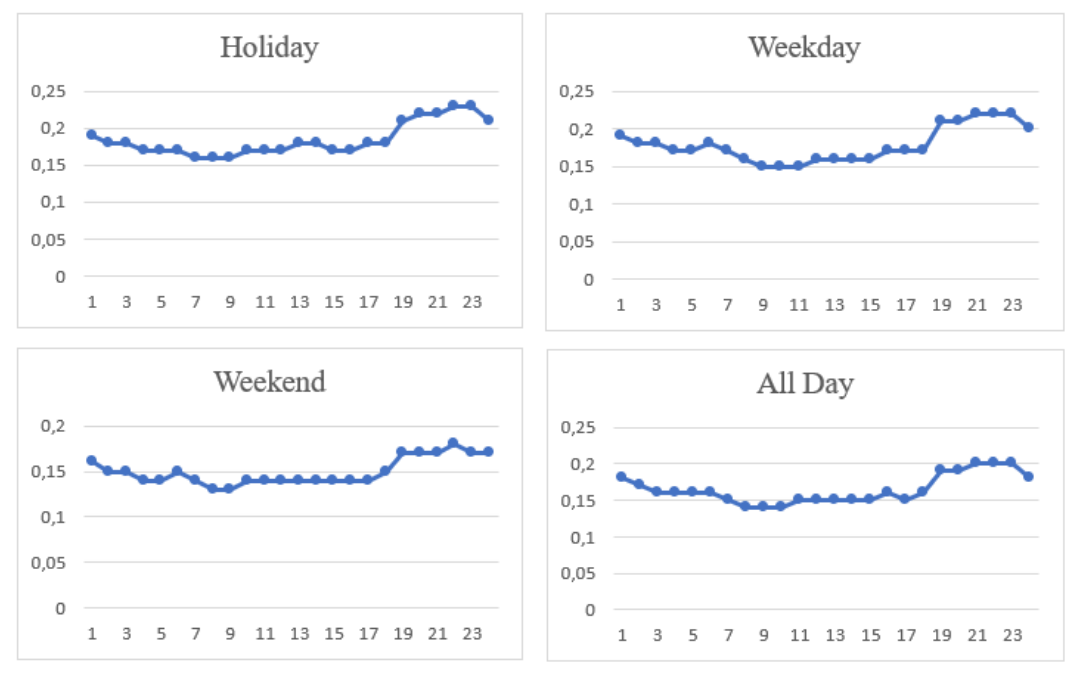

Figure 2 Residential load curve

\subsection{Critical Peak Pricing (CPP)/Time of Use (TOU)}

In this residential load, dynamic rates are designed with the TOU scheme and are combined with CPP at crucial times. To create a dynamic rate with TOU, the electricity provider must be revenue-neutral or there will be no change in income. The goal is for consumers to change their pattern of electricity usage (Faruqui et al., 2009; Faruqui et al., 2017). The first step to designing a residential TOU rate is to determine the off-peak energy rate (calculated during the CPP/TOU design), then determine the peak rate by considering the revenue-neutral existing tariff using the average load of the residential customer profile.

When designing for the Indonesia, the price can be assumed to be a flat rate. The statement is concluded with the following equation:

$$
C P P=T+\frac{C p-30 \% \times C p}{t}
$$

To calculate peak rates, the understanding assumed by the formula is as follows:

$$
\text { Peak }=\frac{T \times 24-\text { top } x \text { tarif off }- \text { peak }}{t p}
$$

\section{RESULTS AND DISCUSSION}

\subsection{Calculation}

The gas power plant has the most expensive electricity cost equal to Rp 92,994/kW-month. The CPP rate was obtained as follows:

$$
C P P=1,467.28+\frac{92,994 \times 12-92,994 \times 12 \times 30 \%}{132}=7,385.08
$$

The off-peak rates were calculated based on the average number of generation cost in the JavaBali system, which is Rp 944.67 / kWh with transmission costs (6.53\%), distribution (2.39\%) and PLN's profit margin of $7 \%$. the following equation was used:

$$
\text { off }- \text { Peak }=(T \times(6.53 \%+2.39 \%+7 \%))=1,099.24
$$

The peak price is:

$$
\text { Peak }=\frac{1467.28 \times 24-16 \times 1099.24}{8}=2,203.36
$$

From these calculations, the dynamic pricing scheme can be obtained as follows: 


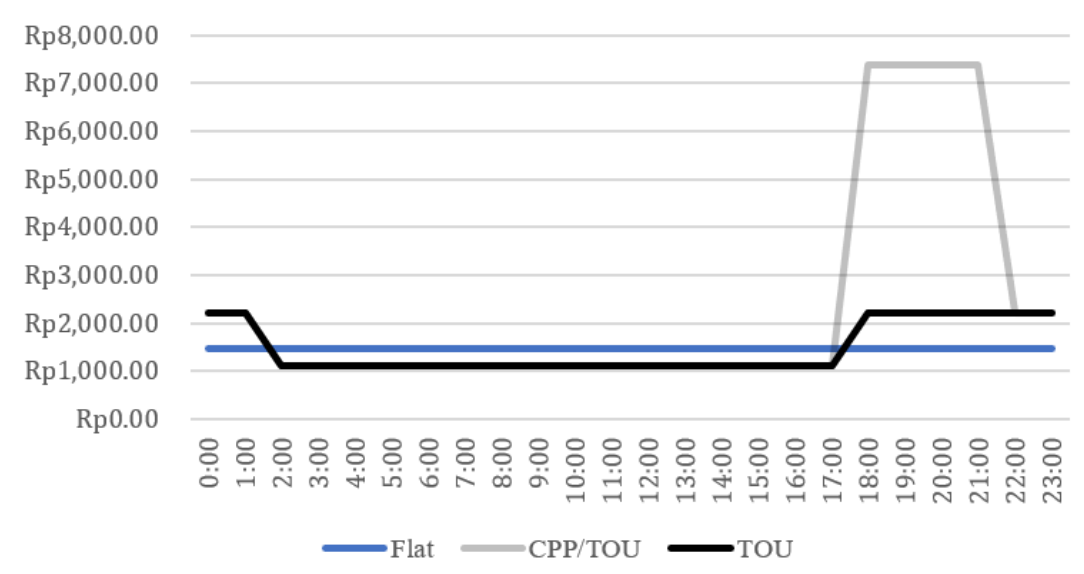

Figure 3 Dynamic pricing schemes

Figure 3 shows three different calculations schemes over 24 hours using dynamic pricing, which are flat, $\mathrm{CPP} / \mathrm{TOU}$, and TOU.

Table 3 Flat, TOU, and CPP/TOU rates

\begin{tabular}{clcc}
\hline \multicolumn{1}{c}{ Method } & \multicolumn{2}{c}{ Period } & Price \\
\hline \multicolumn{1}{c}{ Flat } & \multicolumn{2}{c}{ Time } & $1,467.28$ \\
\cline { 1 - 2 } TOU & Off-Peak & $02.00-18.00$ & $1,099.24$ \\
& Peak & $02.00-18.00$ & $2,203.36$ \\
CPP/TOU & Off-Peak & $02.00-18.00$ & $1,099.24$ \\
& Peak & $02.00-18.00$ & $2,203.36$ \\
& Critical Peak & $02.00-18.00$ & $7,385.08$ \\
\hline
\end{tabular}

Figure 3 and Table 3 describe the flat rates as constant for 24 hours, but while using TOU the rates differs; off-peak time at 18.00-02.00 and peak time at 02.00-18.00.

Table 4 Electricity cost using flat, TOU, and CPP/TOU schemes

\begin{tabular}{|c|c|c|c|c|}
\hline \multirow{2}{*}{ Hours } & \multirow{2}{*}{ Load (kW) } & \multicolumn{3}{|c|}{ Electricity Cost (Rupiah) } \\
\hline & & Flat & Time of Use & $\mathrm{CPP} / \mathrm{TOU}$ \\
\hline 00.00 & 1.59 & 2,333 & 3,503 & 3,503 \\
\hline 01.00 & 0.69 & 954 & 1,432 & 1,432 \\
\hline 02.00 & 0.18 & 264 & 198 & 198 \\
\hline 03.00 & 0.18 & 264 & 198 & 198 \\
\hline 04.00 & 0.18 & 264 & 198 & 198 \\
\hline 05.00 & 0.43 & 631 & 473 & 473 \\
\hline 06.00 & 0.475 & 697 & 522 & 522 \\
\hline 07.00 & 0.36 & 528 & 396 & 396 \\
\hline 08.00 & 0.11 & 161 & 121 & 121 \\
\hline 09.00 & 0.25 & 367 & 275 & 275 \\
\hline 10.00 & 0.36 & 528 & 396 & 396 \\
\hline 11.00 & 0.46 & 675 & 506 & 506 \\
\hline 12.00 & 0.302 & 443 & 332 & 332 \\
\hline 13.00 & 0.293 & 430 & 322 & 322 \\
\hline 14.00 & 0.153 & 224 & 168 & 168 \\
\hline 15.00 & 0.36 & 528 & 396 & 396 \\
\hline 16.00 & 0.25 & 367 & 275 & 275 \\
\hline 17.00 & 0.6 & 880 & 660 & 660 \\
\hline 18.00 & 1.83 & 2,685 & 2,012 & 13,514 \\
\hline 19.00 & 1.73 & 2,538 & 3,812 & 12,776 \\
\hline 20.00 & 1.49 & 2,186 & 3,283 & 11,003 \\
\hline 21.00 & 1.45 & 2,128 & 3,195 & 10,708 \\
\hline 22.00 & 1.4 & 2,054 & 3,085 & 10,339 \\
\hline 23.00 & 1.59 & 2,333 & 3,503 & 3,503 \\
\hline \multicolumn{2}{|c|}{ Total } & 24,464 & 29,258 & 72,214 \\
\hline
\end{tabular}


The CPP/TOU rates reach a critical peak at 18.00-22.00 when the rates increased significantly. The CPP/TOU is similar to TOU scheme, however the CPP/TOU is more accurate. The $\mathrm{CPP} / \mathrm{TOU}$ rates will only operate at the critical peak times that only occur 132 hours per year.

Table 4 describes the comparison of electricity costs between the flat, TOU, and CPP/TOU schemes. The results show the daily total electricity cost using TOU is more expensive compared to flat with a $27 \%$ higher electricity cost at Rp.29,258. The daily total electricity cost using $\mathrm{CPP} / \mathrm{TOU}$ is also more expensive compared to the flat with, a $195 \%$ higher electricity cost at Rp 72,214 .

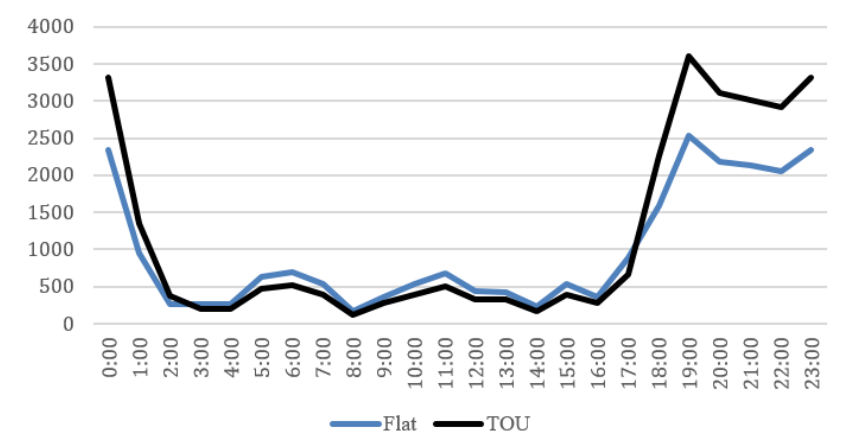

Figure 4 Comparison between flat vs. TOU

Table 4 also shows that the electricity cost of the TOU scheme is higher than the flat scheme due to the load characteristics assumed in the simulation. The peak time of the load occurs at the peak rate of TOU, which significantly differs with the flat scheme.

Figure 5 shows that the electricity cost of the CPP/TOU scheme is higher than the flat scheme, particularly during the critical peak time at 18.00-22.00.

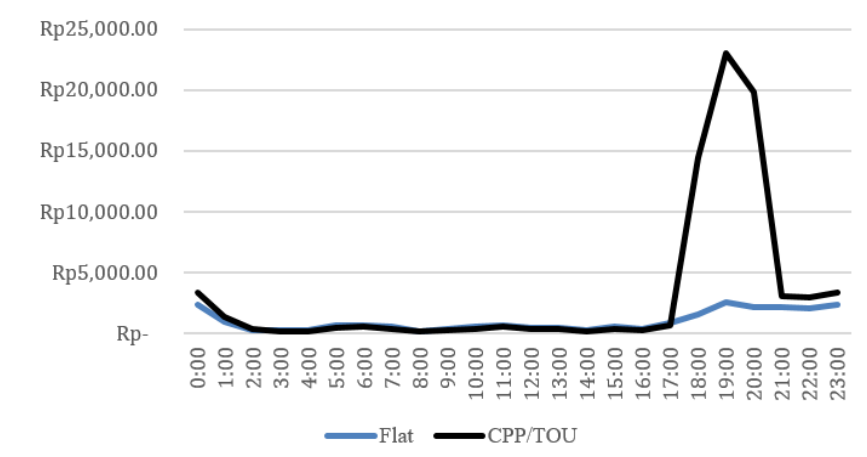

Figure 5 Comparison between flat and CPP/TOU schemes

Table 5 compares the change in electricity cost between dynamic pricing and flat tariff. As previously mentioned, when using TOU electricity cost is increased by $27 \%$ daily, monthly, and annually.

Table 5 Comparison of changes in electricity cost between dynamic pricing and flat tariff

\begin{tabular}{ccc}
\hline Electricity Rate Increase & TOU & CPP/TOU \\
\hline Daily & $27 \%$ & $195 \%$ \\
Monthly & $27 \%$ & - \\
Annually & $27 \%$ & $35 \%$ \\
\hline
\end{tabular}


However, using the CPP/TOU scheme, electricity costs also increased significantly $195 \%$ daily. Because it is uncertain which day with reach critical peak condition, there is no monthly rise in electricity cost. However, annual electricity cost when using CPP/TOU the value differs by $35 \%$.

\subsection{The Effect of Dynamic Pricing on Load Shifting}

In the TOU dynamic pricing scheme, the peak-to-off-peak ratio is $2: 1$, meaning consumers reduce their load usage by $5 \%$ at peak times. In the CPP/TOU scheme the peak-to-off-peak ratio at critical peak is approximately around 3.5:1. We can therefore estimate consumers will reduce their electricity consumption by $8.75 \%$. If using a smart home technology that helps consumers automatically reduce energy consumption at peak times, then consumers will reduce the burden by $9 \%$ in the TOU scheme and $14.25 \%$ in the CPP scheme. Consequently, we can conclude that with the help of this new technology, dynamic pricing schemes will be optimized to reduce consumer electricity usage.

\subsection{The Effect of Dynamic Pricing on Power Plants}

When compared to the percentage difference in Table 6 and the generating output capacity in Table 7, it is clear that using the dynamic pricing scheme reduces plant operations. Thus, the utility company will benefit, as it is not necessary to turn on more power plants and environmentally the gas exhaust from the combustion plants will be reduced.

Table 6 Effects of dynamic pricing on energy consumption

\begin{tabular}{|c|c|c|c|c|c|c|c|c|}
\hline & 18.00 & 19.00 & 20.00 & 21.00 & 22.00 & 23.00 & 00.00 & 01.00 \\
\hline $\begin{array}{l}\text { Java-Bali Power } \\
\text { Plant Load }\end{array}$ & $8,379,233$ & $8,380,258$ & $8,286,425$ & $8,056,544$ & $7,621,938$ & $7,286,653$ & $6,988,897$ & $6,789,584$ \\
\hline Residential Load & $3,150,875$ & $3,151,261$ & $3,111,976$ & $3,029,533$ & $2,866,107$ & $2,740,028$ & $2,628,062$ & $2,553,113$ \\
\hline $\begin{array}{l}5 \% \text { Reduced } \\
\text { Consumption due to } \\
\text { TOU }\end{array}$ & $2,993,332$ & $2,993,698$ & $2,960,177$ & $2,878,056$ & $2,722,801$ & $2,603,027$ & $2,496,659$ & $2,425,458$ \\
\hline $5 \%$ Difference & 157,544 & 157,563 & 155,799 & 151,477 & 143,305 & 137,001 & 131,403 & 127,656 \\
\hline $\begin{array}{l}8.75 \% \text { Reduced } \\
\text { Consumption due to } \\
\text { CPP }\end{array}$ & $2,875,174$ & $2,875,525$ & $2,843,328$ & $2,764,449$ & & & & \\
\hline $8.75 \%$ Difference & 275,702 & 275,735 & 272,648 & 265,084 & & & & \\
\hline
\end{tabular}

Table 7 Generating output capacity

\begin{tabular}{|c|c|c|c|c|c|c|c|c|}
\hline & 18.00 & 19.00 & 20.00 & 21.00 & 22.00 & 23.00 & 00.00 & 01.00 \\
\hline Gasses & 14 & 1,307 & 1,120 & 599 & 214 & 14 & 14 & 14 \\
\hline Diesel & 36,033 & 49,686 & 48,868 & 46,459 & 42,233 & 38,951 & 37,939 & 37,058 \\
\hline Hydroelectric & 283,051 & 447,456 & 442,873 & 434,672 & 389,934 & 341,703 & 313,862 & 294,869 \\
\hline
\end{tabular}

For the near future the green power plant could be installed more to the grid, because the renewable energy technology is ready to be implemented massively and it is working reliably in many countries around the world (Setiawan \& Asvial, 2016).

\section{CONCLUSION}

The dynamic electricity tariff scenario was conducted with two schemes, TOU and a combination of CPP/TOU. In this case the off-peak time of the TOU scheme is between 02.00 and 18.00 with a tariff of Rp 1,099.24 and the peak time of the TOU is between 18.00 and 02.00 with a tariff of $\operatorname{Rp} 2,203.36$. This price is fixed throughout the year. The off-peak time of the CPP/TOU scheme is the same as the TOU scheme. The peak interval is between $20.00-02.00$ and the critical peak interval is 17.00-20.00. The off-peak and CPP/TOU peak rates are the same as the TOU, while the critical peak rates are Rp 7,385.08 for 132 hours per year or approximately $1.5 \%$ a year. Load shifting will occur by $5 \%$ during peak TOU due to its peak-to-off-peak ratio of $2: 1$ and $8.75 \%$ 
during CPP/TOU due to its peak-to-off-peak ratio of 3.5:1. Consumers can benefit my adjusting load usage to dynamic pricing with smart home technology. Dynamic pricing can encourage consumers to reduce electricity consumption at peak times, and has a positive impact by reducing utility grid company expenditure and reducing the emissions/pollutants from fossil fuels.

\section{ACKNOWLEDGEMENT}

This paper was supported and funded by Hibah Penelitian dan Penulisan Tugas Akhir PITTA B UI NKB- 0722/UN2.R3.1/HKP.05.00/2019.

\section{REFERENCES}

Braithwait, S., 2000. Residential TOU Price Response in the Presence of Interactive Communication Equipment. In: A. Faruqui and K. Eakin. (eds.), Pricing in Competitive Electricity Markets. Boston: Kluwer Academic Publishers

EPRI, 2008. Price Elasticity of Demand for Electricity: A Primer and Synthesis, Palo Alto, CA Faruqui, A., Hledik, R., and Tsoukalis, J., 2009. The Power of Dynamic Pricing. The Electricity Journal, Volume 22(3), pp. 42-56

Faruqui, A., Sergici, S., Warner, C., 2017. Arcturus 2.0: A Meta-analysis of Time Varying Rates for Electricity. The Electricity Journal, Volume 30(10), pp. 64-72

Faruqui, A., Sergici, S., 2011. Dynamic Pricing of Electricity in the Mid-Atlantic Region: Econometric Results from the Baltimore Gas and Electric Company Experiment. Journal of Regulatory Economics, Volume 40(1), pp. 82-109

Faruqui, A., Sergici, S., 2010. Household Response to Dynamic Pricing of Electricity: A Survey of 15 Experiments. Journal of Regulatory Economics, Volume 38, pp. 193-225

King, C.S., Chatterjee, S., 2003. Predicting California Demand Response, Public Utilities Fortnightly July 1, American Energy Institute

Setiawan, E.A., Asvial, M., 2016. Renewable Energy's Role in a Changing World. International Journal of Technology, Volume 7, pp. 1280-1282

Taylor, L.D., 1975. The Demand for Electricity: A Survey. The Bell Journal of Economics, Volume 6(1), pp. 74-110

Ton, D., Biviji, M.A., Nagypal, E., Wang, J., 2013. Tool for Determining Price Elasticity of Electricity Demand and Designing Dynamic Price Program. In: IEEE PES Innovative Smart Grid Technologies Conference (ISGT), pp. 1-6 